\title{
A visit to the house of Dr. Shoji Okuda
}

Kenichiro Imagawa, MD, Yokohama, Japan Email:dr@yokobikai.or.jp; Shigeki Inui, MD 0saka, Japan Email: inui@ r-derma.med. osaka-u.ac.jp

Modern hair restoration surgery dates from the time when New York dermatologist, Dr. Norman Orentreich, reported the macrograft technique in 1959.' His technique won general applause; many doctors were trained by him and he was truly honored as the father of hair transplantation. German surgeon Professor H.C. Friederich rediscovered the work of Dr. Shoji Okuda some 30 years ago. In 1939, this Japanese doctor had published a series of five papers using a very similar technique to that described later by Dr. Orentreich. Building on earlier work by Sasakawa and others, he described hair transplantation for cicatricial alopecia, as well as pubic hair, eyebrow, and mustache reconstruction using specially designed punches. This was described in his first paper, and he added histological and experimental studies in human and various animal species in a following publication. ${ }^{2}$

His clinical findings were summarized as following:

- Custom-made punches with a diameter of $1.5-5 \mathrm{~mm}$, were developed. (The Japanese kanji (kanji are a type of ancient Japanese characters) for these instruments can be translated as "round saw.")

- The optimal survival rate of the transplanted hair was obtained by the punches with diameter of $2.5-4 \mathrm{~mm}$ (presumably because of higher transection with smaller punches).

- Scalp hair could survive at any site (eyebrow, mustache, and pubic hair) and continued to grow in size and length due to their inherent nature. For several years, transplanted hair should be trimmed, but it will gradually assimilate to the transplanted area's hair morphology.

- All the cases of hetero-hair-transplantation (transplants from other human scalps) were unsuccessful and the transplanted hair had totally fallen within 30 days, even when familial relationships and blood types were carefully selected.

It was noted that the principle of "donor dominance" and "recipient influence" was suggested but not claimed distinctly, and interestingly, there was no case of hair transplantation for male pattern hair loss mentioned in the papers.

Dr. Okuda's paper was published on the eve of World War II and had been neglected for a long time. I first heard his name from Dr. O'Tar Norwood in 1992 at the Hair Restoration Surgery Symposium in Century City, California. Even after the Okuda papers became well known among hair surgeons, people could read only an abstract as there had been no complete English translation made available to scholars. This was due to the difficulty in reading the 50 printed pages of the original papers, written in old kanji (pictographs) and the almost unintelligible literary style (there was a big change between pre-war and post-war written Japanese). From the early 1990s, Dr. Richard Shiell frequently spoke at meetings and social gatherings of the importance of obtaining a complete English version of the Okuda papers. This was finally achieved in time for the 2003 ISHRS Annual Meeting. It required the dedication and persistence of an older Japanese doctor, my father, Dr. Yoshihiro Imagawa. He was brought up with the old kanji but had two long stays in the United States pursuing post-graduate training in OBGYN and later in Anaesthesia. His 211 pages of neat English translation written in a school exercise book is now one of the ISHRS treasures and several copies were made of this to ensure that they are never lost again.

This document was the basis for the January $2004 \mathrm{Fo}-$ rum article on the Okuda papers written by Dr. Shiell. ${ }^{3}$ The following month, the Forum published several biographies written by my father and me on the other early Japanese hair transplanters-Sasakawa, Tamura, and Fujita - but tracing Dr. Okuda remained elusive. ${ }^{4}$

The others had survived the War and were traced with some difficulty. All of us thought that Dr. Okuda must have died during World War II. The only thing I could discover about him was that he received a PhD from Osaka Imperial University (later renamed the Osaka University). I sent inquiries about him to the Department of Plastic Surgery of Osaka University but, mysteriously, no information could be obtained. I jumped to the conclusion that he graduated from a certain domestic or ex-colonial medical school for army surgeons or that his name was intentionally erased for some reason.

In June 2009, when I was taking a brief look at the Amsterdam ISHRS program, I was attracted to a line that read "Dr. Shoji Okuda (1886-1962): The great pioneer of punch graft hair transplantation." Wow! I lost no time in contacting the presenter of this topic, Dr. Shigeki Inui (Associate professor of Department of Regenerative Dermatology of Osaka University), and asked him how to find out more about Dr. Okuda. According to Dr. Inui, he had found him in the list of medical practitioners at Osaka University library. Dr. Inui was also successful in tracing his grandson, Dr. Takaaki Okuda, who is an ophthalmologist and practices in Nara Cho in Tenri City. This is close to Nara City, the oldest city in Japan. It was the first big metropolis in 710-784 AD and then called Heijokyo. It is famous for many world heritage sites such as the Todai-ji Temple, the world's biggest wooden building, and the biggest bronze Buddha. It is a place where I enjoyed sightseeing with faculty members of the ISHRS Regional Workshop in 2007.

Dr. Inui and I visited Dr. Shoji Okuda's house on July 5, 2009. We were warmly received by his grandsons Drs. Takaaki and Takahiko Okuda (the latter is Professor of Anesthesiology of Kinki University).

The exterior of the house and clinic is antiquated and the façade opens on a small but very historic road. People say the armed forces of Emperor Tenchi marched along this road during the "Jinsin War" in $672 \mathrm{AD}$. The main building was built in 1836 and surrounds the courtyard. Traditional Japanese houses were built of wood and have not much endurance, so a wooden house that has been standing for more than 160 years is quite uncommon.

We obtained the following profile of Dr. Shoji Okuda during the interview. 
He was born in 1886 , as the second son of Kunizo Murai of Morimoto-Cho of Tenri City and adopted by the Okudas. He had been interested in medicine in his childhood and mastered medical textbooks through self education. He didn't enter the medical school at the time as the medical education system in those days had not been rigorous. After the training at Mitsui Charity Hospital and Juntendo Hospital, he passed the Medical Practitioners Qualifying Examination and opened his clinic in 1912. He was a general practitioner but later specialized in ophthalmology, and his clinic was renamed the "Okuda Ophthalmology Clinic" in 1930. He received his PhD from Osaka Imperial University in 1941 for hair research in trichiasis (abnormally positioned eyelashes that grow back toward the eye). He conceived the procedure of oral mucous skin transplantation for the condition, which was afterwards called "the Okuda method." He had been a respected ophthalmologist and passed away at the age of 77 in 1962 . Dr. Okuda didn't talk about hair transplantation in his later years, therefore, his family had not known about this great achievement of his earlier years until quite recently (Figure 1).

After the interview, we were shown into a clinic building adjoining the main house.

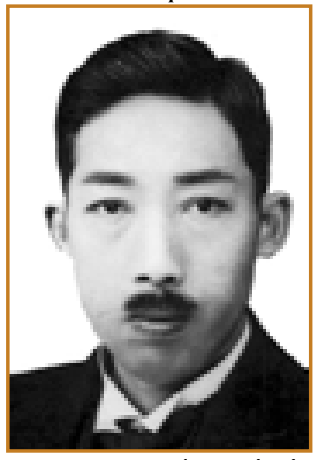

Figure 1. Dr. Shoji Okuda (Courtesy of Dr. Takaaki Okuda)

The appearance of the building was well preserved (Figure 2). The in-patient wards have been rebuilt but the operation suite where Dr. Okuda must have performed many hair transplantation procedures remains unchanged and the dormer window for lighting was quite impressive (Figure 3).

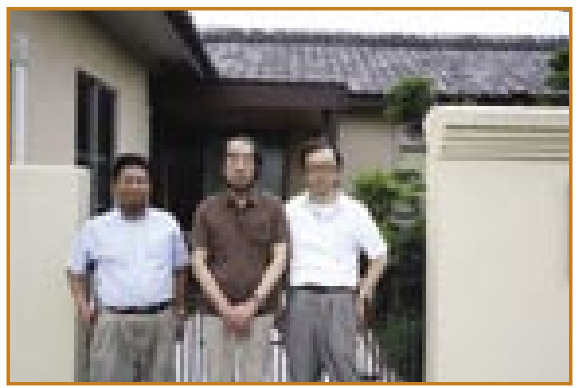

Figure 2. (left to right) Drs. Shigeki Inui, Takaaki Okuda, Takahiko Okuda

Dr. Okuda's grandsons remembered that there were many before/ after pictures of hair surgery in the hall of the clinic that made them feel sick in their childhood. They also remembered

that there had been an animal house, later demolished, where there had been many cages of rabbits, guinea pigs, and mice. I was surprised to learn that all the animal experiments were done in his clinic and not in a university laboratory.

I was amazed that Dr. Okuda's rickshaw for house calls was still preserved in the current clinic car park. It even had a detachable plate giving his name and phone number. Such loving retention of the possessions of a grandfather would rarely be seen in the world these days, and demonstrates a Japanese veneration of their older generation that is poorly understood in the West.

All sorts of medical practice equipment such as the documents, literature, medical devices, microscope, dressing materials, specimens, wax models of eye diseases, chemicals, and drugs were all saved in several warehouses, crowded and time-worn, just like in the tomb of Tutankhamen. Even the grandsons had not been in the room for nearly 30 years.

We discovered one wooden sign board with the writing: Cosmetic Surgery Consultation on Request, Mon., Wed. \& Friday. Takaaki asserted that this sign belonged to Shoji. There were also numerous before/after pictures of hair surgery covered with dust. We should re-examine the widely accepted opinion that Dr. Orentreich was the first who performed hair transplantation for male pattern hair loss. It is very possible that these were

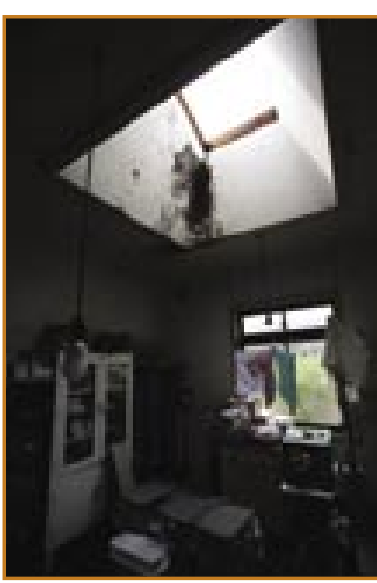

Figure 3. Dr. Okuda's Operating Room performed by Dr. Okuda but not written about in journals because of the prevailing prejudice from Japanese colleagues

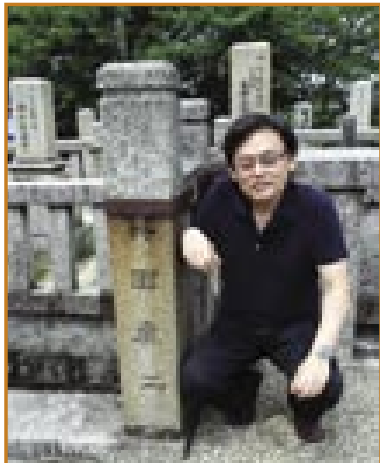

Figure 4. The author at Dr. Okuda's grave post regarding "non-essential" cosmetic surgery. Dr. Shiell told me that this still carried a stigma in the far more liberal country of Australia, even as late as 1967 , when he was getting started.

After we left the Okuda house, we visited Shoji's grave and, with bowed heads, reported to him the story of modern hair transplantation (Figure 4).

In mid-August, I heard from Takaaki that he had spent a whole day in the warehouses to search for Shoji's original punches, and finally he found them. He visited our clinic to give us two punches $(1.5 \mathrm{~mm}$ and $2 \mathrm{~mm}$ ), and they have become my treasured possessions (Figure 5).

\section{References}

1. Orentreich, N. Autografts in alopecia and other selected dermatological conditions. Ann NY Acad Sci. 1959; 83:463-479.

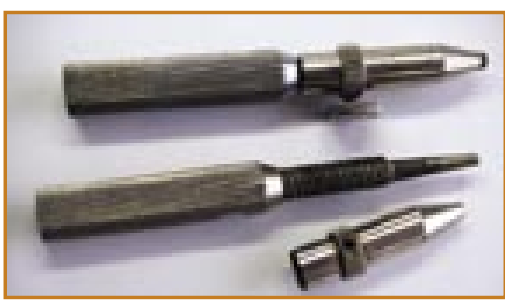

Figure 5. Dr. Okuda's original punches $(1.5$ and $2 \mathrm{~mm})$
2. Okuda, S. Clinical and experimental studies on hair transplantation of living hair. Jap J Dermatol Uro. 1939; 46:537-587 (in Japanese).

3. Shiell, R.C. The Okuda papers. Hair Transplant Forum Int'l. 2004; 14:1-6.

4. Imagawa, Y., and K. Imagawa. Tamura, Sasakawa, and Fujita now translated. Hair Transplant Forum Int'l. 2004; 14:41-46.

5. Inui, S., and S. Itami. Dr. Shoji Okuda (1886-1962): The great pioneer of punch graft hair transplantation. I Dermatol (Japanese Dermatological Association). 2009; 36:561-562. 
A visit

from page 201

\section{A note from Richard C. Shiell, MBBS Melbourne, Australia}

It has been 80 years since the publication of Dr. Sasakawa's paper on hair transplantation. Although he was unsuccessful with heterograft transplantation, he really started something and we had a succession of papers on autografts by Drs. Shoji Okuda, Tamura, and Fujita over the next 15 years. The Pacific War then brought an end to these writings and the hair research "baton" passed to the United States. The Japanese contributions were forgotten for 30 years.

Many mysteries have been unraveled by our Japanese compatriot Dr. Kenichiro Imagawa in recent times and published in the Forum. It appears that NONE of the early Japanese authors were killed in the 1939-45 war, as long supposed. Dr. Sasakawa died at age 45 in 1932, Dr. Tamura died in 1977, and Dr. Fujita in 1985. Only Dr. Okuda proved elusive. The latest research from Japan shows that he too died with his boots "off" in 1962 , at the age of 77 . He was a distinguished Opthalmologist of all things, not a dermatologist or plastic surgeon as previously supposed!

We still have no evidence that he worked with cases of male pattern hair loss but the prevailing medical ethics at the time may have made him reluctant to mention this in his published work. Further perusal of the old records held by the Okuda family may yet reveal more treasures. The unraveling of this story makes interesting reading and a hearty thank-you to Drs. Kenichiro Imagawa and Shigeki Inui for their detective work. $\diamond$

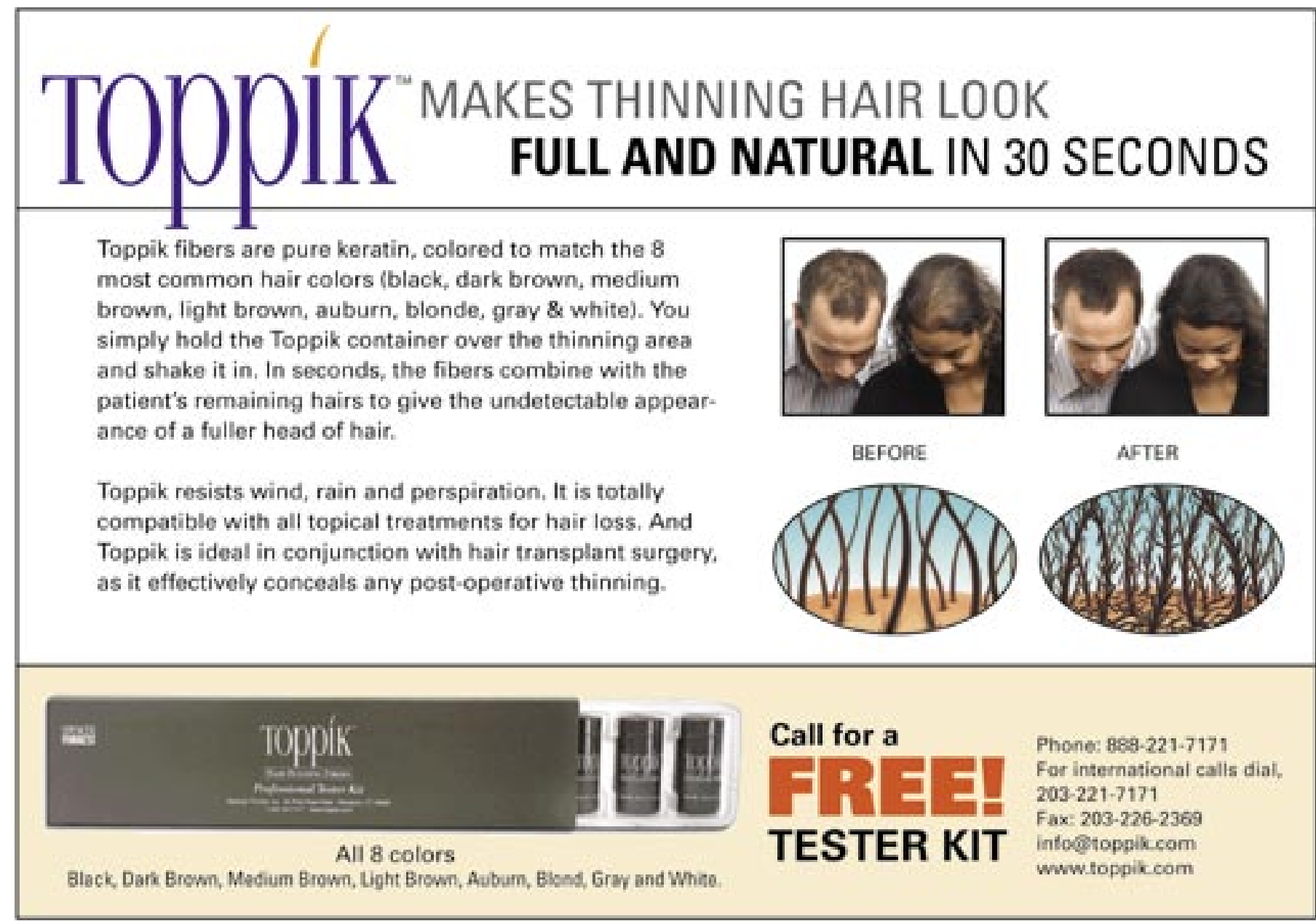

